\title{
Moonlighting Together: Faculty (Creative) Writing Groups
}

\author{
Erick Piller \\ Nicholls State University
}

\begin{abstract}
Articles across the disciplines have praised faculty writing groups as a means of boosting scholarly productivity and encouraging collaboration. However, the faculty writing groups described in this body of literature typically focus on research-based and other conventionally academic forms of writing. In this presentation, I will consider the extent to which this work on faculty writing groups can be productively applied to the case of faculty creative writing groups. Such groups often inhabit a liminal space between academic and private life, meeting informally and including members who would not expect to benefit professionally from the publication of their creative writing. In addition, I will employ autoethnographic methods in conjunction with theoretical concepts from the literature in order to reflect on the informal faculty creative group that I have participated in since the Fall 2018 semester. In this way, I hope to arrive at generalizable insights about my own motivations and experiences and those of my fellow group members.
\end{abstract}

